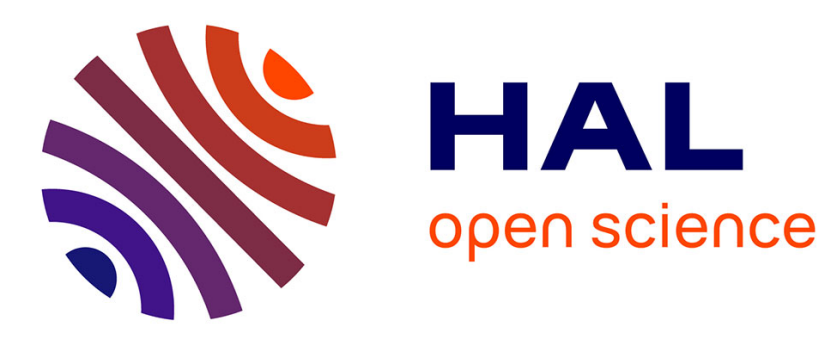

\title{
Thiazolidinediones induce osteocyte apoptosis and increase sclerostin expression
}

Guillaume Mabilleau, Aleksandra Mieczkowska, M.-E. Edmonds

\section{To cite this version:}

Guillaume Mabilleau, Aleksandra Mieczkowska, M.-E. Edmonds. Thiazolidinediones induce osteocyte apoptosis and increase sclerostin expression. Diabetic Medicine, 2010, 27 (8), pp.925-932. 10.1111/j.1464-5491.2010.03048.x . hal-03349506

\section{HAL Id: hal-03349506 \\ https://univ-angers.hal.science/hal-03349506}

Submitted on 20 Sep 2021

HAL is a multi-disciplinary open access archive for the deposit and dissemination of scientific research documents, whether they are published or not. The documents may come from teaching and research institutions in France or abroad, or from public or private research centers.
L'archive ouverte pluridisciplinaire HAL, est destinée au dépôt et à la diffusion de documents scientifiques de niveau recherche, publiés ou non, émanant des établissements d'enseignement et de recherche français ou étrangers, des laboratoires publics ou privés. 


\title{
Original Article: Treatment
}

\section{Thiazolidinediones induce osteocyte apoptosis and increase sclerostin expression}

\author{
G. Mabilleau, A. Mieczkowska and M. E. Edmonds* \\ Institute of Musculoskeletal Sciences, University of Oxford, Nuffield Department of Orthopaedics, Rheumatology and Musculoskeletal Sciences, Oxford \\ and *Diabetic Foot Clinic, King's College Hospital, London, UK
}

Accepted 28 May 2010

\begin{abstract}
Aims Thiazolidinediones (TZDs) are associated with a higher risk of bone fracture in women compared with men. The aim of the present study was to investigate whether TZDs could influence osteocyte behaviour and contribute to the skeletal phenotype observed in TZD-treated patients.
\end{abstract}

Methods The murine MLO-Y4 cell line was used as a source of osteocytes. These cells were cultured for $24 \mathrm{~h}$ with $0,10^{-8} \mathrm{M}$, $10^{-7} \mathrm{M}, 10^{-6} \mathrm{M}, 10^{-5} \mathrm{M}$ or $10^{-4} \mathrm{M}$ of pioglitazone, rosiglitazone or troglitazone in the presence or absence of $17 \beta$-oestradiol. The extent of osteocyte apoptosis was assessed, as was the expression of the bone formation inhibitor sclerostin and receptor activator for nuclear factor $\mathrm{\kappa B}$ ligand (RANKL) also.

Results In the absence of $17 \beta$-oestradiol, pioglitazone, rosiglitazone and troglitazone induced osteocyte apoptosis dosedependently even at the lowest concentration of $10^{-8}$ M. Furthermore, the expression of sclerostin but not RANKL was significantly increased in TZD-treated cultures compared with untreated cultures. The presence of $17 \beta$-oestradiol significantly reduced TZD-induced osteocyte apoptosis and also sclerostin up-regulation.

Conclusions These findings therefore raise the potential concern of using TZDs in post-menopausal women where the lack of oestrogen would not prevent osteocyte apoptosis and sclerostin up-regulation and may aggravate the reduction in bone mass in these patients.

Diabet. Med. 27, 925-932 (2010)

Keywords apoptosis, osteocyte, RANKL, sclerostin, thiazolidinedione

Abbreviations PPAR- $\gamma$, peroxisome proliferator-activated receptor gamma; RANKL, receptor activator for nuclear factor $\kappa \mathrm{B}$ ligand; TZD, thiazolidinedione

\section{Introduction}

Thiazolidinediones (TZDs), also known as glitazones, represent a class of pharmaceutical compounds, approved for the treatment of Type 2 diabetes mellitus (Type 2 DM). They act via the nuclear receptor peroxisome proliferator-activated receptor gamma (PPAR- $\gamma)$. Some adverse effects have been reported with TZDs, such as weight gain, fluid retention and increased risks of congestive heart failure. Also, there is an increased risk of bone fracture, especially in women, but the cause is unknown [1-4]. Bones contain several cell types,

Correspondence to: Guillaume Mabilleau, PhD, University of Oxford, NDORMS, The Botnar Research Centre, Windmill road, Oxford OX3 7LD, UK. E-mail: guillaume.mabilleau@ndorms.ox.ac.uk including osteoblasts (the bone-forming cells), osteoclasts (bone-resorbing cells) and osteocytes, which control bone remodelling. Adipocytes are also found inside the bone marrow. PPAR- $\gamma$ activation is thought to increase adipocyte differentiation at the expense of osteoblasts in vitro $[5,6]$. Furthermore, in vivo models showed that TZDs decrease bone formation and increase adiposity in the bone marrow, although bone resorption was not affected [7-11]. However, the increased fracture rate in females cannot be explained only by the increase in adipogenesis, which also occurs in men.

The effects of TZDs on osteocytes are poorly understood. In the adult skeleton, osteocytes make up more than $90-95 \%$ of all bone cells compared with 4-6\% osteoblasts and 1-2\% osteoclasts [12]. These cells are regularly dispersed throughout the mineralized matrix and connected to each other and to 
osteoblasts and osteoclasts on the bone surface through dendritic processes generally radiating toward the bone surface and the blood supply. Osteocytes can conduct and control both bone resorption and bone formation. Osteocytes express receptor activator for nuclear factor $\mathrm{\kappa B}$ ligand (RANKL) along their dendritic processes and support osteoclast formation and resorption [13]. Osteocytes also express sclerostin, a bone formation inhibitor, and are thought to participate in the maintenance of the bone mass [14]. Oestrogens are potent survival factors for osteocytes, as demonstrated by the increase in osteocyte death following oestrogen deprivation [15]. Osteocytes are also targeted by drugs affecting bone metabolism because of their connections with blood vessels [16,17].

The aim of this study was to investigate how TZDs could influence osteocyte behaviour. We found that TZDs induced osteocyte apoptosis in a dose-dependent manner and these cells also demonstrated increased expression of the bone inhibitor sclerostin whilst the expression of RANKL was unchanged. Furthermore, addition of oestrogen in the culture prevented TZD-induced osteocyte apoptosis and expression of sclerostin.

\section{Material and methods}

\section{Reagents}

Rosiglitazone and troglitazone were purchased from Cayman Chemicals (Ann Arbor, MI, USA). Pioglitazone was purchased from Molekula (Shaftesbury, UK) and 17ß-oestradiol from Calbiochem (Nottingham, UK). Alpha-MEM, foetal bovine serum (FBS), bovine calf serum, penicillin and streptomycin were purchased from Lonza (Wokingham, UK). All other chemicals were purchased from Sigma-Aldrich (Poole, UK).

\section{Cell culture}

The murine long bone-derived osteocytic cell line MLO-Y4 was kindly provided by Professor L. Bonewald (University of Missouri-Kansas City, Kansas City, MO, USA). Cells were cultured in alpha minimal essential medium ( $\alpha \mathrm{MEM}$ ) supplemented with $5 \%$ FBS, $5 \%$ bovine calf serum, $100 \mathrm{U} / \mathrm{ml}$ penicillin and $100 \mu \mathrm{g} / \mathrm{ml}$ streptomycin. Cells were plated at $1 \times 10^{4}$ cells $/ \mathrm{cm}^{2}$ on collagen type I-coated plates, as described previously [18].

\section{Apoptosis assay}

Increased plasma membrane permeability that occurs during the apoptosis process can be visualized using trypan blue, a dye that is excluded from living cells and is incorporated into the cells when they are undergoing apoptosis [19]. Briefly, MLO-Y4 cells were plated in 24-well plates and cultured in the presence of $10^{-8} \mathrm{M}, 10^{-7} \mathrm{M}, 10^{-6} \mathrm{M}, 10^{-5} \mathrm{M}$ and $10^{-4} \mathrm{M}$ of pioglitazone, rosiglitazone and troglitazone. In a parallel experiment, in order to assess whether oestrogens could protect osteocytes from apoptosis, MLO-Y4 cells were pretreated for $30 \mathrm{~min}$ with $17 \beta$ oestradiol at a concentration of $10^{-7} \mathrm{M}$ prior to incubation with TZDs. After $24 \mathrm{~h}$, the cell culture supernatant containing the floating cells was collected and put in previously labelled eppendorf tubes. Each well was washed in PBS before trypsin was added to detach adherent cells. The mixture containing detached adherent cells was collected and pooled in the eppendorf tube containing the cell culture supernatant. Cells were spun at $650 \mathrm{~g}$ for $10 \mathrm{~min}$, (IEC Micromax RF, ThermoFisher Scientific, Basingstoke, UK) the supernatant was removed carefully and cells were incubated with trypan blue $0.04 \%$ and transferred into a haemocytometer. Living (clear) and dead (blue) cells were counted under light microscope examination and the percentage of dead cells was determined for each condition as follow:

$$
\begin{gathered}
\% \text { of dead cells }=100 \times(\text { number of dead cells }) / \\
\quad \text { (number of dead cells }+ \text { number of living cells })
\end{gathered}
$$

Cells were also stained using $1 \mu \mathrm{g} / \mathrm{ml}$ DAPI nuclear stain and apoptotic cells were characterized by cell shrinkage, plasma membrane blebbing (transmitted light) and nuclear condensation (fluorescent light). Digital images of cells were captured at $20 \times$ magnification using an Olympus BX40 microscope fitted with an Olympus DP-70 camera (Olympus UK Ltd, Southend-on-sea, UK). For analysis, three wells per treatment and six fields per well were analysed. Within each field, the total number of apoptotic cells was assessed and expressed as the percentage of apoptotic cells/field.

In order to further demonstrate the apoptotic nature of the TZD response, a specific caspase-3 inhibitor (Z-DEVD-FMK; R\&D Systems Europe, Abingdon, UK) was used to inhibit terminal effector caspase-3. Cells were pre-incubated for $45 \mathrm{~min}$ with $50 \mu \mathrm{M}$ of Z-DEVD-FMK prior to the addition of $10^{-6} \mathrm{M}$ TZD. At the end of the experimental period, the cells were washed with PBS and fixed in $4 \%$ paraformaldehyde solution and the percentage of apoptotic cells was assessed microscopically after DAPI staining as described above.

\section{Western blot}

MLO-Y4 cells were cultured for $24 \mathrm{~h}$ on $25-\mathrm{cm}^{2}$ flasks precoated with collagen type I with the different TZDs in the presence or absence of $10^{-7} \mathrm{M} 17 \beta$-oestradiol. Cells were washed in cold PBS and homogenized in lysis buffer containing $50 \mathrm{~mm}$ Tris-hydrogen chloride $(\mathrm{HCl}) \quad \mathrm{pH} 7$, $100 \mathrm{~mm}$ sodium chloride $(\mathrm{NaCl}), 50 \mathrm{~mm}$ sodium fluoride (NaF), $3 \mathrm{~mm}$ sodium orthovanadate $\left(\mathrm{Na}_{3} \mathrm{VO}_{4}\right)$, protease inhibitor cocktail and 1\% Nonidet P-40. Samples were spun at $12,000 \mathrm{~g}$ for $30 \mathrm{~min}$ at $4{ }^{\circ} \mathrm{C}$, the supernatant was collected and protein concentration was determined using a BCA protein assay kit (Pierce Biotechnology, Rockford, IL, USA). Samples (20 $\mu$ g per lane) were run on a $10 \%$ acrylamide gel and blotted onto a polyvinylidene difluoride (PVDF) membrane. The membranes were washed in Tris-buffered saline (TBS) and 
blocked with $5 \%$ bovine serum albumin. Samples were incubated overnight with one of the following specific antibodies for caspase-3 and activated caspase-3 (antibodies nos 9665 and 9664; Cell Signalling Technology, Danvers, MA, USA), sclerostin or membrane-bound RANKL (R\&D Systems Europe) and $\beta$-actin (Sigma-Aldrich). Subsequently, the membranes were washed in TBS and incubated with the appropriate secondary antibodies coupled to horseradish peroxidase (HRP). Immunoreactive bands were visualized using an ECL kit (Amersham, Little Chalfont, UK). The degree to which the different markers was induced was determined by normalizing the specific signal to that of actin using ImageJ Freeware (National Institutes of Health) and the results were expressed as protein of interest/actin ratio.

\section{Detection of soluble RANKL}

In order to determine the levels of soluble RANKL, MLO-Y4 cells were exposed to pioglitazone, rosiglitazone or troglitazone for $24 \mathrm{~h}$ in the presence or absence of $17 \beta$-oestradiol. Conditioned media were collected, centrifuged at $800 \mathrm{~g}$ for $30 \mathrm{~min}$, aliquoted and frozen at $-80^{\circ} \mathrm{C}$ prior to evaluation of the levels of murine soluble RANKL with a commercially available kit (Murine Quantikine Kit; R\&D Systems Europe) according to the manufacturer's protocol. According to the manufacturer, the minimum dose detectable (MDD) of soluble RANKL was $31.2 \mathrm{pg} / \mathrm{ml}$.

\section{Statistical analysis}

All experiments were carried out in triplicate and repeated at least three times. Results were expressed as mean \pm standard deviation. Non-parametric Mann-Whitney U-test was used to compare the differences between the groups using the SPSS statistical software release 14.0. (SPSS Inc., Chicago, IL, USA). Differences at $P<0.05$ were considered significant.

\section{Results}

\section{TZDs induced osteocyte apoptosis}

In order to assess whether TZDs could induce osteocyte death/apoptosis, the number of dead cells was assessed by trypan blue exclusion and the number of apoptotic cells was assessed by counting cells with piknotic nuclei after DAPi staining (Fig. 1a). Compared with untreated cultures, pioglitazone, rosiglitazone and troglitazone induced a significant dose-dependent osteocyte apoptosis up to a concentration of $10^{-6} \mathrm{M}$. At higher concentration, cell death occurred independently of apoptosis. Indeed, even at a very low concentration of $10^{-8} \mathrm{M}$, pioglitazone, rosiglitazone and troglitazone induced osteocyte apoptosis with an average of $3.8 \pm 0.5,3.3 \pm 0.4$ and $3.4 \pm 0.3 \%$, respectively. The number of apoptotic osteocytes augmented with increased concentration of TZDs and reached $35 \pm 15,35.6 \pm 4.4$ and $39.4 \pm 4.6 \%$ after treatment with $10^{-6} \mathrm{M}$ of pioglitazone, rosiglitazone and troglitazone, respectively.

One of the crucial steps of apoptosis is the activation of caspase- 3 by proteolytic cleavage. Levels of intact and cleaved caspase- 3 were determined by western blot (Fig. 1b). Compared with untreated control cultures, a dose-dependent activation of caspase- 3 was observed in TZD-treated cultures, even at the low concentration of $10^{-8} \mathrm{M}$.

Furthermore, TZD-induced osteocyte apoptosis was blocked by the use of a caspase- 3 inhibitor (Fig. 1c), confirming the deleterious effects of these molecules on osteocytes.

\section{Apoptotic osteocytes expressed increased levels of sclerostin but not RANKL}

Osteocytes are intimately connected with osteoblasts and osteoclasts at the bone surface and are considered as orchestrators of bone remodelling. In order to assess whether TZDs could affect the expression of bone remodelling mediators by apoptotic osteocytes, the expression of sclerostin and RANKL was determined by western blot and ELISA in the presence of $10^{-8} \mathrm{M}, 10^{-7} \mathrm{M}$ or $10^{-6} \mathrm{M}$ TZDs. Compared with untreated control cultures, sclerostin expression was dramatically increased in all TZD cultures (Fig. 2a). Indeed, rosiglitazone was the most potent TZD to induce sclerostin, followed by troglitazone and pioglitazone. However, the expression of membrane-bound RANKL was not up-regulated in response to any TZD treatments compared with untreated cultures (Fig. 2b). Similarly, levels of soluble RANKL were not significantly different from untreated cultures (Fig. 2c).

\section{Oestrogens prevented TZD-induced osteocyte apoptosis}

We also evaluated whether pretreatment with $10^{-7} \mathrm{M} 17 \beta-$ oestradiol could protect osteocytes from TZDs-induced apoptosis (Fig. 3). Pretreatment with 17ß-oestradiol considerably reduced TZD-induced apoptosis of osteocytes in pioglitazone-, rosiglitazone- and troglitazone-treated cultures (Fig. 3a). Similarly, oestrogen treatment prevented caspase-3 activation in pioglitazone-, rosiglitazone- and troglitazonetreated cultures (Fig. 3b).

\section{Oestrogen prevented increased expression of sclerostin}

Furthermore, we investigated whether pretreatment with $17 \beta$ oestradiol could abolish the up-regulation of sclerostin observed in TZD alone-treated cultures. We observed that in pioglitazone-, rosiglitazone- and troglitazone-treated cultures, pretreatment with oestrogen prevented sclerostin up-regulation (Fig. 4a). Indeed, levels of sclerostin were significantly decreased compared with untreated cultures. Also, pretreatment with oestrogen did not modify the expression profile of membranebound RANKL in response to pioglitazone, rosiglitazone or troglitazone (Fig. 4b). However, pretreatment with oestrogen 
(a)
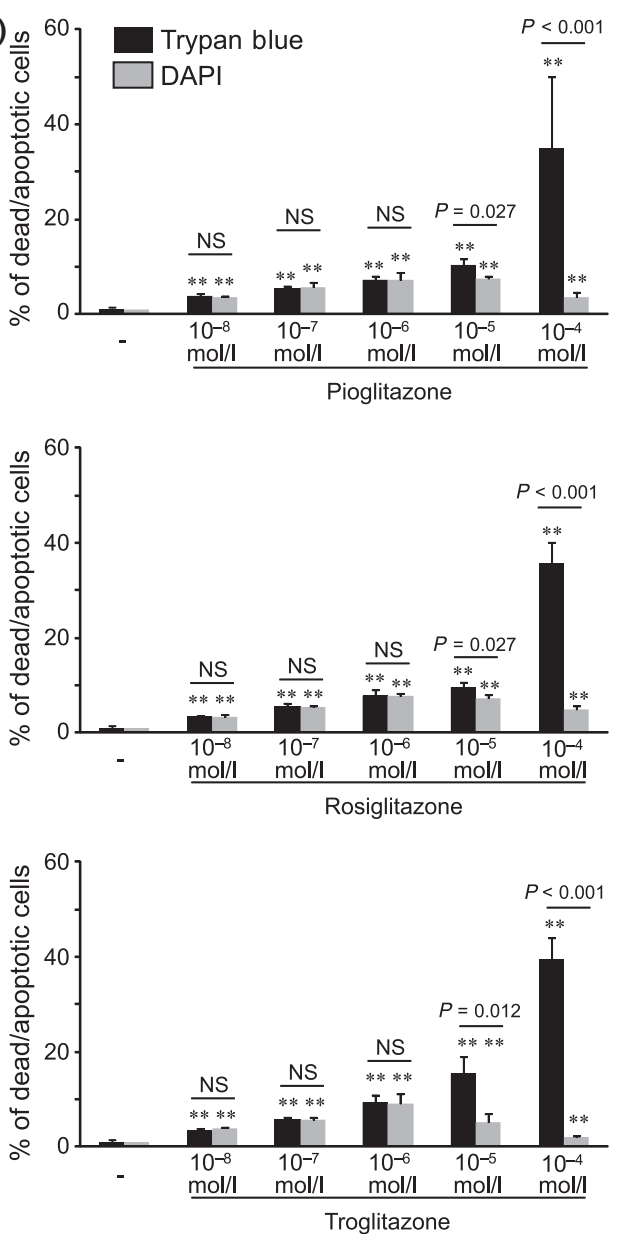

(b)
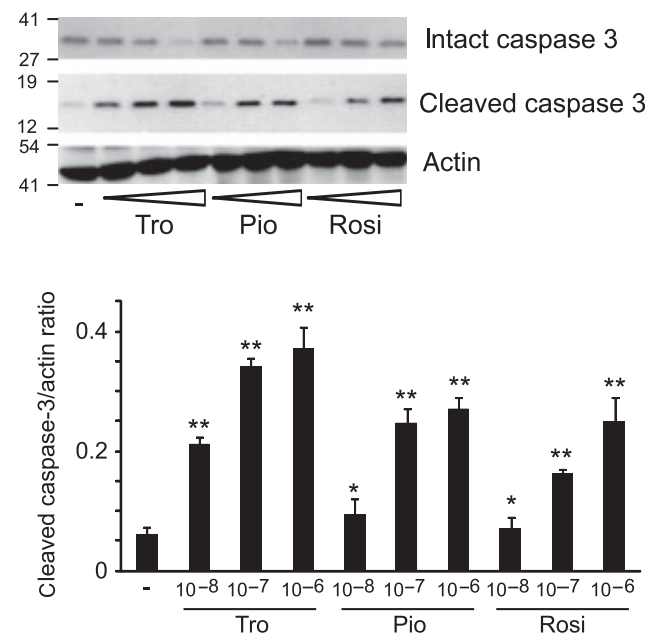

(c)

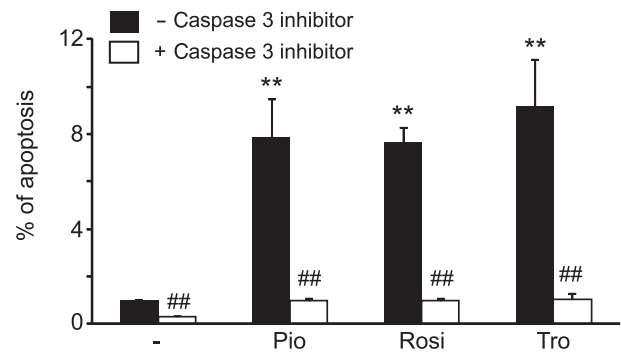

FIGURE 1 Effects of thiazolidinediones (TZDs) on osteocyte apoptosis. (a) Percentage of osteocyte death/apoptosis after 24-h treatment with TZDs estimated by trypan blue assay (black bars) and DAPI (grey bars). (b) Expression of intact and cleaved caspase-3 and actin after 24-h treatment with TZDs. * $\mathrm{p}<0.05$ vs. untreated cultures (c) Percentage of apoptosis in the presence (white bars) or absence (black bars) of a caspase- 3 inhibitor and treatment with $10^{-6} \mathrm{M}$ TZDs. $\dagger P<0.01$ vs. untreated cultures and $₫ P<0.01$ vs. cells treated in the absence of caspase- 3 inhibitor. NS, not significant.

significantly decreased the levels of soluble RANKL, compared with untreated cells, to those similar to the $17 \beta$-oestradiol alonetreated cells (Fig. 4c).

\section{Discussion}

The present study demonstrated that TZDs are potent inducers of osteocyte apoptosis, which was associated with increased expression of the bone formation inhibitor sclerostin at the surface of the osteocytes, although the expression of RANKL, one of the main osteoclastogenic factors, was unchanged. Furthermore, we demonstrated that oestrogens prevented TZD-induced osteocyte apoptosis and sclerostin up-regulation.

Short-term clinical trials of TZDs have demonstrated substantial bone loss in women [20]. Most of these trials have been undertaken in post-menopausal women [20]. In the Diabetes Outcome Progression Trial (ADOPT) study, which highlighted the higher risk of bone fracture under rosiglitazone therapy, $77 \%$ of women were post-menopausal [3]. Further evidence that rosiglitazone and pioglitazone causes bone loss has come from animal studies. In vitro, TZDs promote bone marrow stromal cell adipogenesis at the expense of osteogenesis [5,6]. It was therefore expected that TZD capacity to activate PPAR- $\gamma$ would diminish osteoblast differentiation while increasing bone marrow adipogenesis, as demonstrated recently in vivo [11]. However, although these models indicate a negative effect of TZDs on osteoblast differentiation and activity, another explanation for increased bone loss could be bone cell apoptosis. An alternative mechanism has been reported previously by Soroceanu et al. in a mouse model where injection of rosiglitazone $3 \mathrm{mg} \mathrm{kg}^{-1}$ day $^{-1}$ over a period of 90 days induced a 5-fold increase in osteoblast/osteocyte apoptosis without significantly affecting the percentage of fat in the bone marrow [21]. However, these authors did not report the individual figures for apoptotic osteoblasts and apoptotic osteocytes, making it difficult to conclude whether this was an osteoblast- or osteocyte-driven mechanism. In the present study, we have demonstrated that the use of pioglitazone, rosiglitazone and troglitazone dose-dependently induced osteocyte apoptosis 
(a)
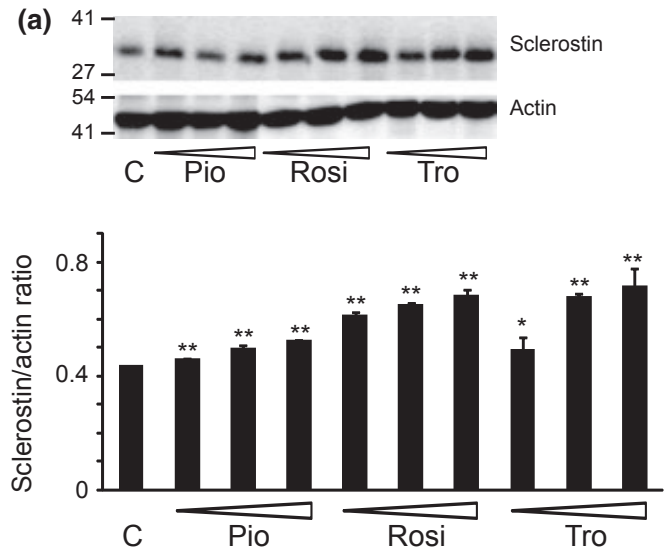

(b)
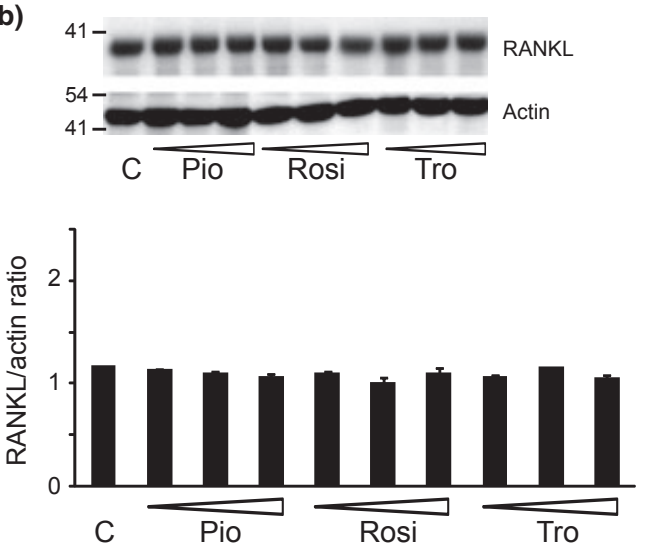

(c)

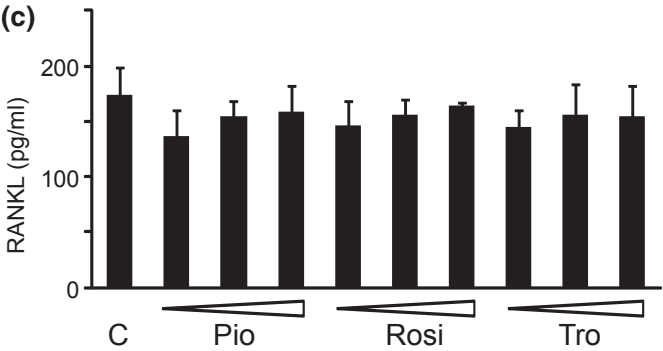

FIGURE 2 Expression of bone remodelling mediators after $24 \mathrm{~h}$ with $10^{-8} \mathrm{M}, 10^{-7} \mathrm{M}$ and $10^{-6} \mathrm{M}$ thiazolidinediones (TZDs). Expression of sclerostin (a), membrane-bound RANKL (b) and soluble RANKL (c). ${ }^{*} P<0.05, \dagger P<0.01$ vs. untreated cultures.
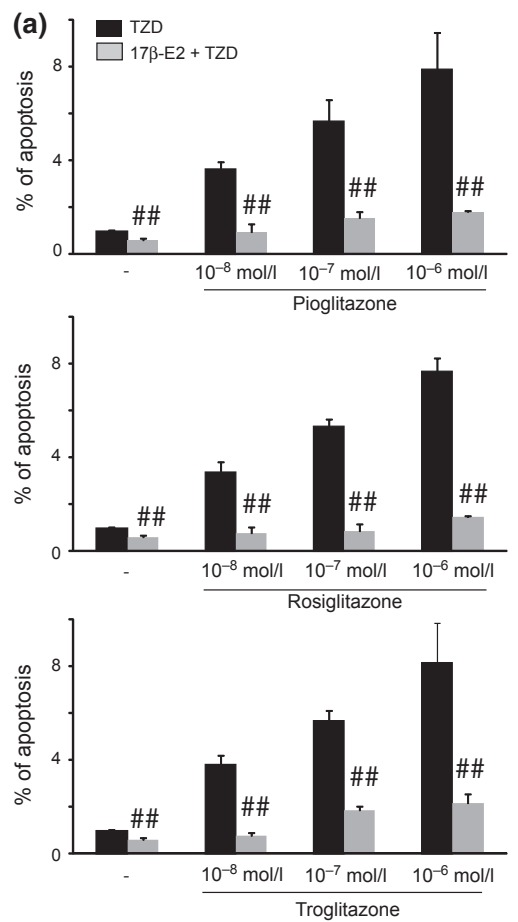

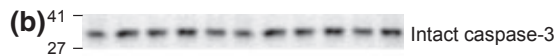

$19-$

$12-$

54 -

c

Cleaved caspase-3

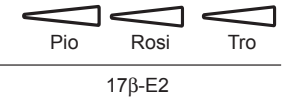

-E2 
(a) 41
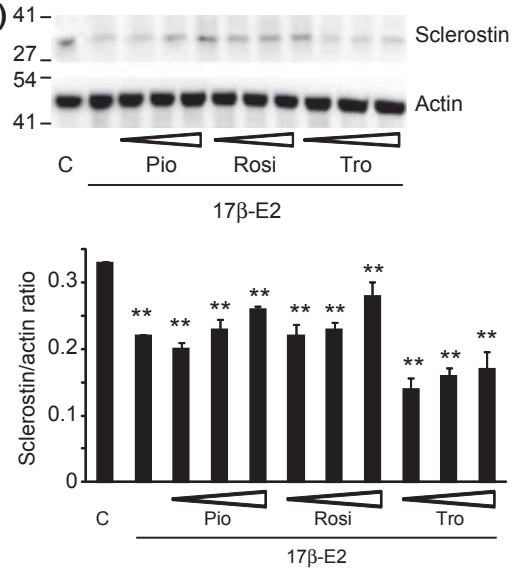

(b) 41
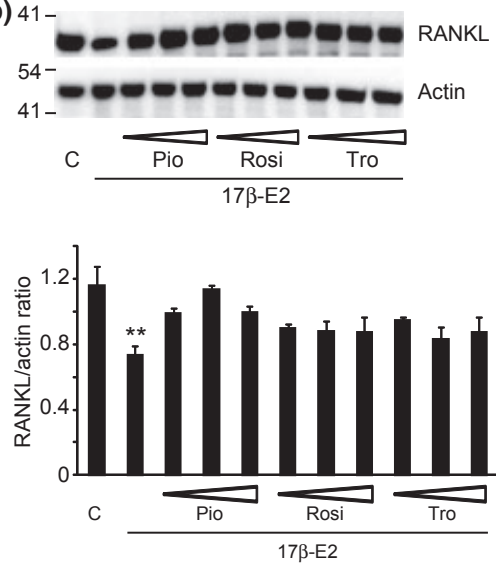

(c)

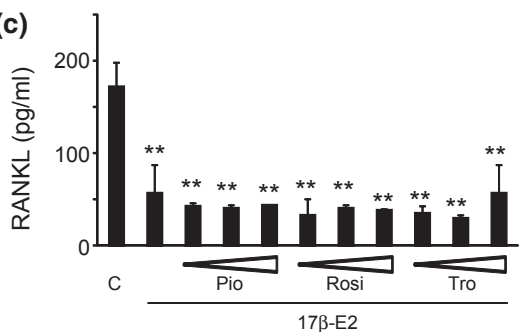

FIGURE 4 Oestrogen pretreatment prevents sclerostin up-regulation. MLO-Y4 cells were pretreated for 30 min with $17 \beta$-oestradiol $10^{-7} \mathrm{M}$ before $10^{-8} \mathrm{M}$, $10^{-7} \mathrm{M}$ or $10^{-6} \mathrm{M}$ thiazolidinediones (TZDs) were added in the culture. Expression of sclerostin (a), membrane-bound RANKL (b) and soluble RANKL

(c) were determined after 24 h. $* P<0.01$ vs. untreated cultures.

up to a concentration of $10^{-6} \mathrm{M}$ and was accompanied by increased expression of the bone formation inhibitor sclerostin in our model. However, a certain controversy had emerged with the expression of sclerostin in MLO-Y4 cells. Yang et al. reported that MLO-Y4 cells expressed low levels of sclerostin mRNA [22]. Furthermore, Papanicolaou et al. also reported that no sclerostin expression was detected in mature MLO-Y4 cells [23]. In contrast, Vincent $e t$ al. reported previously that sclerostin was induced in response to TNF-related weak inducer of apoptosis (TWEAK) in the MLO-Y4 cell line [24]. We have also observed that the expression of sclerostin by MLO-Y4 cells tends to disappear after several in vitro passages and one possible explanation for this controversy could be the differentiation state of MLO-Y4 at which the expression of sclerostin is investigated. In contrast, in this model the osteoclastic factor, RANKL (membrane-bound and soluble), was not affected even although at a concentration of $10^{-6} \mathrm{M}$, where the extent of osteocyte apoptosis was maximum in the cultures. The concentration of $10^{-6} \mathrm{M}$ is commonly in the range of serum levels of TZDs, which typically are comprised of between 2.2 and $8 \mu \mathrm{M}[25,26]$.

It has been recently recognized that TZDs can induce cell apoptosis and these pharmaceutical compounds may be useful in treating certain types of cancer [27-29]. Interestingly, troglitazone appears to have the highest proapoptotic effect [30]. We also observed that troglitazone was the more potent TZD in inducing osteocyte apoptosis. PPAR- $\gamma$-independent effects of TZDs are suspected to be responsible for the pro-apoptotic effects of these drugs [31,32]. Troglitazone can cause mitochondrial dysfunction, followed by increased permeability, calcium influx and nuclear condensation leading to apoptosis [33]. However, in our study, we did not assess whether the observed effect of TZDs on osteocytes was (i) PPAR- $\gamma$ dependent or independent and (ii) whether mitochondrial function was affected. These points need to be addressed in the future to understand better how TZDs induce osteocyte apoptosis and sclerostin up-regulation.

In the present study, we also found that pretreatment of osteocytes with oestrogen prior to incubation with TZDs prevented not only osteocyte apoptosis but also sclerostin up-regulation. In vivo, the anti-apoptotic effect of oestrogens has been demonstrated by the administration of $17 \beta$-oestradiol into ovariectomized mice. This dramatically reduces the levels of osteocyte apoptosis observed in vehicle-treated ovariectomized animals [15]. Plotkin et al. reported that the molecular mechanism by which oestrogens prevent osteocyte apoptosis is mediated through rapid activation of the ERK pathway leading to increased activity of the transcription factor Elk1 and rapid phosphorylation of the pro-apoptotic factor BAD [16]. In our study, it is plausible that the cellular integration of anti-apoptotic signals, mediated by the administration of 17ß-oestradiol, and pro-apoptotic signals, caused by TZDs, resulted in the inhibition of osteocyte apoptosis.

In conclusion, we have demonstrated that, in our model, in the absence of oestrogens, TZDs caused osteocyte apoptosis and 


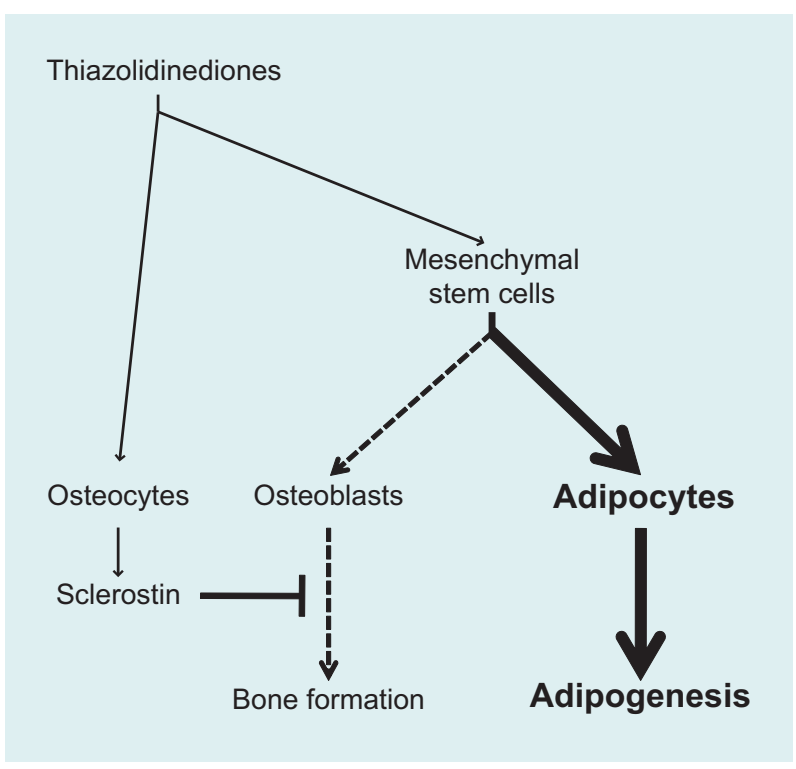

FIGURE 5 Skeletal effects of thiazolidinediones. TZDs promote adipocyte differentiation at the expense of osteoblast differentiation leading to decrease bone mass. Furthermore, TZDs induce osteocyte apoptosis and increase expression of sclerostin which may also contribute to the decreased bone mass.

sclerostin up-regulation. However, administration of oestrogens significantly prevented these events. The skeletal effects of TZDs may be thus summarized in Fig. 5. Although TZDs promote bone marrow stromal cell adipogenesis at the expense of osteoblasts, and as such contribute to decreased bone formation, our study brings a new arm to this simplified view; as a consequence of TZDs, apoptotic osteocytes express higher levels of sclerostin, a potent bone formation inhibitor, and this may contribute to decreased bone formation. However, further studies are required to understand fully the molecular mechanisms by which TZDs induced osteocyte apoptosis and especially sclerostin up-regulation in other osteocytic models. Nevertheless, our findings raise the potential concern of using TZDs in post-menopausal women where the lack of oestrogen would not prevent osteocyte apoptosis and sclerostin up-regulation. This may aggravate the reduction in bone mass in these patients and lead to bone fracture.

\section{Competing interests}

Nothing to declare.

\section{Acknowledgments}

The authors are grateful for the support provided by the Musculoskeletal Biomedical Research Unit in partnership with Nuffield Department of Orthopaedics, Rheumatology and Musculoskeletal Sciences, University of Oxford. GM is also a recipient of a Diabetes UK-RD Lawrence Fellowship (grant 09/0003836).

\section{References}

1 Dormandy JA, Charbonnel B, Eckland DJ, Erdmann E, MassiBenedetti M, Moules IK et al. Secondary prevention of macrovascular events in patients with type 2 diabetes in the PROactive Study (PROspective pioglitAzone Clinical Trial In macroVascular Events): a randomised controlled trial. Lancet 2005; 366: 1279-1289.

2 Kahn SE, Haffner SM, Heise MA, Herman WH, Holman RR, Jones NP et al. Glycemic durability of rosiglitazone, metformin, or glyburide monotherapy. N Engl J Med 2006; 355: 2427-2443.

3 Kahn SE, Zinman B, Lachin JM, Haffner SM, Herman WH, Holman RR et al. Rosiglitazone-associated fractures in type 2 diabetes: an Analysis from A Diabetes Outcome Progression Trial (ADOPT). Diabetes Care 2008; 31: 845-851.

4 Meymeh RH, Wooltorton E. Diabetes drug Pioglitazone (Actos): risk of fracture. CMAJ 2005; 177: 723-724.

5 Lecka-Czernik B, Gubrij I, Moerman EJ, Kajkenova O, Lipschitz DA, Manolagas SC et al. Inhibition of Osf2/Cbfa1 expression and terminal osteoblast differentiation by PPAR $\gamma 2$. J Cell Biochem 1999; 74: 357-371.

6 Lecka-Czernik B, Moerman EJ, Grant DF, Lehmann JM, Manolagas SC, Jilka RL. Divergent effects of selective peroxisome proliferator-activated receptor- $\gamma 2$ ligands on adipocyte versus osteoblast differentiation. Endocrinology 2002; 143: 2376-2384.

7 Berberoglu Z, Gursoy A, Bayraktar N, Yazici AC, Bascil Tutuncu N, Guvener Demirag N. Rosiglitazone decreases serum bone-specific alkaline phosphatase activity in postmenopausal diabetic women. J Clin Endocrinol Metab 2007; 92: 3523-3530.

8 Glintborg D, Andersen M, Hagen C, Heickendorff L, Hermann AP. Association of pioglitazone treatment with decreased bone mineral density in obese premenopausal patients with polycystic ovary syndrome: a randomized, placebo-controlled trial. J Clin Endocrinol Metab 2008; 93: 1696-1701.

9 Grey A, Bolland M, Gamble G, Wattie D, Horne A, Davidson J et al. The peroxisome proliferator-activated receptor- $\gamma$ agonist rosiglitazone decreases bone formation and bone mineral density in healthy postmenopausal women: a randomized, controlled trial. J Clin Endocrinol Metab 2007; 92: 1305-1310.

10 Jennermann C, Triantafillou J, Cowan D, Pennink B, Connolly K, Morris D. Effects of thiazolidinediones on bone turnover in the rat. J Bone Miner Res 1995; 10: S241.

11 Rzonca SO, Suva LJ, Gaddy D, Montague DC, Lecka-Czernik B. Bone is a target for the antidiabetic compound rosiglitazone. Endocrinology 2004; 145: 401-406.

12 Bonewald LF. Osteocytes. In: Rosen CJ, ed. Primer on the Metabolic Bone Diseases and Disorders of Mineral Metabolism. Washington DC: American Society for Bone and Mineral Research, 2008: $22-27$.

13 Zhao S, Zhang YK, Harris S, Ahuja SS, Bonewald LF. MLO-Y4 osteocyte-like cells support osteoclast formation and activation. J Bone Miner Res 2002; 17: 2068-2079.

14 van Bezooijen RL, Roelen BA, Visser A, van der Wee-Pals L, de Wilt $\mathrm{E}$, Karperien M, et al. Sclerostin is an osteocyte-expressed negative regulator of bone formation, but not a classical BMP antagonist. J Exp Med 2004; 199: 805-814.

15 Huber C, Collishaw S, Mosley JR, Reeve J, Noble BS. Selective estrogen receptor modulator inhibits osteocyte apoptosis during abrupt estrogen withdrawal: implications for bone quality maintenance. Calcif Tissue Int 2007; 81: 139-144.

16 Plotkin LI, Aguirre JI, Kousteni S, Manolagas SC, Bellido T. Bisphosphonates and estrogens inhibit osteocyte apoptosis via distinct molecular mechanisms downstream of extracellular signal-regulated kinase activation. J Biol Chem 2005; 280: 7317-7325. 
17 Plotkin LI, Lezcano V, Thostenson J, Weinstein RS, Manolagas SC, Bellido T. Connexin 43 is required for the anti-apoptotic effect of bisphosphonates on osteocytes and osteoblasts in vivo. J Bone Miner Res 2008; 23: 1712-1721.

18 Kato Y, Windle JJ, Koop BA, Mundy GR, Bonewald LF. Establishment of an osteocyte-like cell line, MLO-Y4. J Bone Miner Res 1997; 12: 2014-2023.

19 Bellido T, Plotkin LI. Detection of apoptosis of bone cells in vitro. Methods Mol Biol 2008; 455: 51-75.

20 Schwartz AV. TZDs and bone: a review of the recent clinical evidence. PPAR Res 2008; 2008: 297893-297898.

21 Soroceanu MA, Miao D, Bai XY, Su H, Goltzman D, Karaplis AC. Rosiglitazone impacts negatively on bone by promoting osteoblast/osteocyte apoptosis. I Endocrinol 2004; 183: 203-216.

22 Yang W, Harris MA, Heinrich JG, Guo D, Bonewald LF, Harris SE. Gene expression signatures of a fibroblastoid preosteoblast and cuboidal osteoblast cell model compared to the MLO-Y4 osteocyte cell model. Bone 2009; 44: 32-45.

23 Papanicolaou SE, Phipps RJ, Fyhrie DP, Genetos DC. Modulation of sclerostin expression by mechanical loading and bone morphogenetic proteins in osteogenic cells. Biorheology 2009; 46: 389-399.

24 Vincent C, Findlay DM, Welldon KJ, Wijenayaka AR, Zheng TS, Haynes DR et al. Pro-inflammatory cytokines TNF-related weak inducer of apoptosis (TWEAK) and TNF $\alpha$ induce the mitogenactivated protein kinase (MAPK)-dependent expression of sclerostin in human osteoblasts. J Bone Miner Res 2009; 24: 1434-1449.

25 Gillies PS, Dunn CJ. Pioglitazone. Drugs 2000; 60: 333-345.

26 Plosker GL, Faulds D. Troglitazone: a review of its use in the management of type 2 diabetes mellitus. Drugs 1999; 57: 409-438.
27 Lucarelli E, Sangiorgi L, Maini V, Lattanzi G, Marmiroli S, Reggiani $\mathrm{M}$ et al. Troglitazione affects survival of human osteosarcoma cells. Int J Cancer 2002; 98: 344-351.

28 Wang T, Xu J, Yu X, Yang R, Han ZC. Peroxisome proliferatoractivated receptor $\gamma$ in malignant diseases. Crit Rev Oncol Hematol 2006; 58: 1-14.

29 Yu HN, Noh EM, Lee YR, Roh SG, Song EK, Han MK et al. Troglitazone enhances tamoxifen-induced growth inhibitory activity of MCF-7 cells. Biochem Biophys Res Commun 2008; 377 : 242-247.

30 Feinstein DL, Spagnolo A, Akar C, Weinberg G, Murphy P, Gavrilyuk $\mathrm{V}$ et al. Receptor-independent actions of PPAR thiazolidinedione agonists: is mitochondrial function the key? Biochem Pharmacol 2005; 70: 177-188.

31 Palakurthi SS, Aktas H, Grubissich LM, Mortensen RM, Halperin JA. Anticancer effects of thiazolidinediones are independent of peroxisome proliferator-activated receptor $\gamma$ and mediated by inhibition of translation initiation. Cancer Res 2001; 61: 6213-6218.

32 Wei S, Yang J, Lee SL, Kulp SK, Chen CS. PPAR $\gamma$-independent antitumor effects of thiazolidinediones. Cancer Lett 2009; 276: 119-124.

33 Haskins JR, Rowse P, Rahbari R, de la Iglesia FA. Thiazolidinedione toxicity to isolated hepatocytes revealed by coherent multiprobe fluorescence microscopy and correlated with multiparameter flow cytometry of peripheral leukocytes. Arch Toxicol 2001; 75: 425-438. 